the cause of day and night (4-6), the relationship between the earth and the moon (4-6), the motion of the earth and planets (4-6), major structures in the universe including the solar system (4-6), the phases of the moon (7-9), theoretical origins of the solar system and the universe (7-9), and astronomical equipment including telescopes (7-9).

At Central Michigan University we have developed a laboratory course for general astronomy students that is based almost entirely on practical and elementary concepts. Activities include learning to identify the prominent constellations, bright stars, and naked-eye planets; charting the motions of planets and seeing how this affects their visibility; observing and understanding diurnal and seasonal changes in the sky; knowing the phases of the moon, their times of visibility, and the cause; understanding the different types of eclipses; learning the components and the use of a small astronomical telescope; learning the use of star maps and the celestial globes; and viewing the sun, moon and planets. A copy of the laboratory manual may be obtained by contacting the author.

\title{
TEACHING OBSERVATIONAL ASTRONOMY AS A LABORATORY COURSE FOR NON-MAJORS
}

\author{
Yong H. Kim \\ Department of Astronomy, Geosciences \& Physics, Saddleback College, \\ Mission Viejo, California 92692, U.S.A.
}

\section{Introduction}

Since antiquity, doing astronomy means basically stepping outside, looking upward, and considering the widest environment. Thus any undergraduate astronomy program, no matter how diverse its course offering, is incomplete without observational astronomy. For example, some California community colleges offer several courses including such titles as "Man and the Cosmos," "Final Stellar States," "Astronomy Enrichment," and "Astronomical Myths, Mysteries \& Fallacies," but do not offer "Observational Astronomy." As a teaching astronomer, I question the wisdom and honesty of such practice of proliferation solely based on sensationalism. An introductory lecture course and an observational lab course must be the core of lower-division undergraduate astronomy education. Anything else, in my opinion, is peripheral.

This paper intends to address the importance of the teaching of observational astronomy as a liberal studies lab course. Instead of delineating specific course materials or instructional methods, I aim to discuss epistemological goals which, I 
believe, should help to answer clearly (a) what a student should learn and (b) what pedagogic attitudes and approaches should be taken to ensure effective teaching.

\section{A Survey}

It is generally believed that astronomy is so popular that a college (if we exclude highly specialized schools) cannot afford not to offer at least introductory astronomy courses. However, my survey of 200 randomly chosen colleges and universities across the United States gives an unexpected result. I found that 52 schools (26\%) offer no introductory astronomy courses at all. Among the 148 colleges and universities that provide at least one introductory-level astronomy course, 98 offer lecture-only courses. The remaining 52 institutions have introductory courses that require laboratory hours. Only 45 schools offer observational astronomy courses that are clearly designated as being taught at night. Interestingly, 35 colleges and universities list multiple lower-division courses beyond the introductory level without offering observational astronomy.

According to my survey, observational astronomy belongs to a minority (only about $30 \%$ ) of the schools with lower-division astronomy programs. Whatever the reason, this tendency for the majority to ignore observational astronomy is disturbing. Some may argue that introductory courses with lab hours are sufficient. They are definitely much better than those without lab sessions. Any astronomer would agree that "daytime" lab hours simply cannot substitute for a "nighttime" observational course.

\section{Some Insight About Undergraduate Teaching}

According to some critics, our liberal education, even at the best colleges, has been so cheapened that it is like a carnival with too many competing and contradicting courses and with no substantive vigor and clear direction (Bloom, 1987). Our students are wasting their "charmed" four years of undergraduate learning with many questionable courses and studies, all overemphasizing trendiness and popularization and heading towards a dead-end. It is truly tragic that good courses in natural sciences must compete with these other courses for resources.

College students today generally avoid taking courses in science and mathematics unless these subjects are required for their major or graduation. Those who involuntarily take science, particularly physical science, usually bring with them self-destructive attitudes about their ability to learn. It is almost impossible, unless we change human nature, to make involuntary learning a pleasure. However, if we make sure that the level, quality, and standard of the course are consistent with what we should expect of the student, we can possibly overcome this problem.

Many students find astronomy fascinating in itself. Also, astronomy is a wonderful subject because of its inexhaustible nature (Bondi, 1970). Thus astronomy as a college-level subject has tremendous possibilities for transforming non-majors into scientifically astute citizens. For many students, introductory astronomy is the last (for some probably the only) exposure to science in their lives. Teaching astronomers 
must not waste this opportunity of winning future pro-astronomy taxpayers. This opportunity is not without a challenge: These students have little or no background in science. Most of them are scared to death of mathematics. How do we engage such students to learn a quantitative science like astronomy? It can only be done by the teacher's creativity, flexibility, and adaptability in dealing with the immediate circumstances.

\section{Laboratory Experience: What Should It Mean?}

For non-science students, lab courses are unique among undergraduate educational experiences. Lab courses are supposed to provide opportunities "to learn by getting one's fingers dirty." We find a deeper insight into what a lab science course should mean to the student in the following quotation: "An introductory course in physical science done entirely with the printed word, pencil, and paper cannot convey a true picture of the nature of scientific enterprise... The essence of learning in science is participation: doing and asking and making errors and learning from them... The lab work is not primarily to train you in certain dexterous actions. It is only to give the genuine feel of that world which we can at best pallidly describe on paper in words or symbols. It is above all to give the scene of what is meant by abstraction" (Holcomb and Morrison, 1974). Any practicing scientist can intuitively appreciate the power and insight of the above quotation. Yet that is the problem of every teaching scientist: we understand so well what a lab experience means that we have the difficulty of reading the same statement through the eyes of a student, who may not have even the vaguest idea why a lab course is required.

All lab courses are taxing propositions to all parties involved: the student, the teacher, and the department. The student is required to put in more hours than in other courses (for a 3-unit observational course perhaps even 4 hours per week plus 12 hours to be additionally arranged). For the teacher, a lab course requires a lot more work than a normal science course by a factor of 2 or 3 . Particularly in the case of observational astronomy, the teacher's enthusiasm, energy, and interest are imperative for success because of the nighttime observing activities. Some argue that actual telescope work by non-majors is of very little use (Booth and McNally, 1980 ), with which I strongly disagree. The department must be resourceful enough to provide at least a dark-night observing site and related necessities (teaching assistants, portable or transportable telescopes, means of transportation, etc.).

The most important epistemological goal of any lab course is to provide the students with an opportunity to verify themself some pre-ordained knowledge (or scientific truth) by practicing experimental skills. The student may gain from lab exercises the sense to recognize the difference between what is real and what is based on someone else's judgments, perceptions, and assumptions. Thus the ideal lab course should be one in which we can challenge the student with the existential question of what scientific truth is and how scientists go about discovering it. The goal is specifically not to tell the student what truth is (even if we could know), or even to tell him when and if he has verified the truth. On the contrary, the 
worst possible lab course is one that emphasizes memorization as the main task, or requires mostly cook-book type experiments, or stresses nothing but the plug-andchug manipulation of numbers.

\section{A Few Maxims Worth (I Hope) Considering}

Quality is not accidental, but must be designed. A successful course is based on the basic concept of "design integrity," which means designing a course so it will fulfill its goals well and reliably despite unavoidable imperfections.

Perfection of means cannot correct confusion of goals. Setting a manageable and cohesive set of well-defined goals is the utmost important aspect of effective teaching. The goals must match the backgrounds of the students and resources available.

For better products, use fewer parts. Less detail does not necessarily make the course less proper. Relatively minor subjects should not be brought up just for the sake of completeness. We cannot give knowledge neatly wrapped up with no loose ends. The strength of astronomy, I think, is that it allows us to present science as unfolding, advancing, and never completed.

Popularity alone will not always make a course interesting. Astronomy is very popular. However, students often find that it is interesting up to the first lecture or those first few pages in the text. Astronomy can be made dreadfully dull like any other subject unless the teacher makes an active effort to make his or her lectures and presentations interesting. Also, we should not be afraid to spend more time and effort on those topics that students enjoy most.

Seeing it once is incomparably better than hearing about it one hundred times. This old Chinese proverb sums up very well what observational astronomy is all about. Therefore, weather permitting, every class session must be held out outdoors. The night sky provides inexhaustible things for seeing.

\section{Conclusion}

Despite all sorts of logistical problems, complex issues, and unexpected glitches, I still believe that observational astronomy is very worthwhile, not only because it is the core curriculum of astronomy education but also because we can create in the minds of the educated public of the future a foundation of public appreciation of what astronomers are doing. Many alumni of my observational course have joined the ranks of amateur astronomers.

\section{References}

Bloom Alan. The Closing of the American Mind. New York: Simon \& Schuster, Inc. 1987.

Booth, R.S., and D. McNally. "Undergraduate Astronomy Teaching." Quarterly Journal of the Royal Astronomical Society 21:32-53; 1980.

Bondi, H. "Astronomy of the Future." Quarterly Journal of the Royal Astronomical 
Society 11:443-450; 1970.

Holcomb, D.F., and Philip Morrison. My Father's Watch: Aspects of the Physical World. (Englewood Cliffs, New Jersey: Prentice Hall), 1974.

\section{Comment}

Jay M. Pasachoff: We must not forget solar observations - we have one star that we can observe in the daytime, when it happens to be most convenient for many students. Further, the sun changes from day to day, so there is always something new to be seen. 